\title{
Pathophysiology of High Flow Access and Surgical Flow Reduction Procedures
}

\author{
Takehisa Nojima $^{1, *(D)}$ and Yasuki Motomiya ${ }^{2}$ \\ 1 Nojima Vascular Access Clinic, Kobe 651-2273, Japan \\ 2 Suiyukai Medical Corporation, Kashihara 634-0007, Japan; big_dr_cam_cam@yahoo.co.jp \\ * Correspondence: nva-info@nva-c.jp
}

Citation: Nojima, T.; Motomiya, Y. Pathophysiology of High Flow Access and Surgical Flow Reduction Procedures. Kidney Dial. 2021, 1 , 36-46. https://doi.org/10.3390/ kidneydial1010007

Academic Editors: Junji Uchida, Toshihide Naganuma,

Yoshiaki Takemoto and

Hideki Kawanishi

Received: 24 April 2021

Accepted: 9 July 2021

Published: 11 July 2021

Publisher's Note: MDPI stays neutral with regard to jurisdictional claims in published maps and institutional affiliations.

Copyright: (C) 2021 by the authors. Licensee MDPI, Basel, Switzerland. This article is an open access article distributed under the terms and conditions of the Creative Commons Attribution (CC BY) license (https:/ / creativecommons.org/licenses/by/ $4.0 /)$.

\begin{abstract}
High flow access (HFA) is a condition in which hemodynamics is affected by a flow rate that is larger than the blood flow required for hemodialysis. HFA sometimes causes high output heart failure, venous hypertension, and dialysis access steal syndrome. Flow reduction is effective for improving symptoms, and various surgical procedures have been reported. HFA is recognized as a well-developed type of access due to its good access sound, thrill, and vessel diameter; also, HFA probably has good patency if not intervened with by flow reduction. Therefore, the blood flow reduction procedures used to treat HFA need to minimize disadvantages such as access thrombosis, insufficient blood flow, aneurysm formation, and infection due to therapeutic intervention while, at the same time, achieving symptom improvement and long-term patency. The surgical procedure used to correct HFA must be highly reproducible and simple. This article reviews the pathophysiology and surgical flow reduction procedures for HFA.
\end{abstract}

Keywords: high flow access; flow reduction procedure; arteriovenous fistula; high output heart failure; venous hypertension; dialysis access steal syndrome

\section{Introduction}

Vascular access is a lifeline for dialysis patients, as it allows them to maintain stable hemodialysis. The number of chronic dialysis patients in Japan is increasing every year, and it had reached 344,640 by the end of 2019 (2019 Annual Dialysis Data Report, JSDT Renal Data Registry). After the creation of an AVF, the blood flow volume of the arteriovenous fistula (AVF) gradually increases and can provide the blood flow required for hemodialysis [1]. Sometimes, a blood flow that far exceeds the flow required for hemodialysis can be reached. Through its effect as a left-to-right extracardiac shunt, the arteriovenous fistula can increase the cardiac workload and increase sympathetic nervous system activity through increases in the heart contractility, heart rate, stroke volume, and cardiac output (CO) to maintain blood pressure [2,3]. High flow access may cause high-output cardiac failure, venous hypertension, steal syndrome, and even systemic steal syndrome [4]. An overview of the pathophysiology and surgical procedures used for high flow access is given below.

\section{Development and Remodeling after AVF Creation}

When hemodialysis is planned for patients with end-stage renal disease, which vascular access is appropriate will be examined [5]. Compared with other vascular accesses such as arteriovenous graft (AVG), central venous catheter, and arterial superficialization [6], AVF is considered to be the most suitable VA for hemodialysis due to its high patency rate and low frequency of thrombosis and infection [7]. After the creation of AVF, various effects occur in the vein, artery, and systemic circulation. By the creation of the fistula, a large amount of blood flows from the artery to the vein via the anastomosis due to the pressure gradient. AVF development is a complex vascular remodeling. Large amounts of blood flow through the access circuit, increased blood pressure or velocity, increased wall shear stress, dilation of arteries and veins, and structural changes in the vessel wall 
are factors in remodeling [8]. Dammers et al. investigated the effect of shear stress on vessel diameter during the perioperative period of AVF creation. Their results indicate that after AVF creation, an acute increase in shear stress results in an acute increase of vessel diameter $[9,10]$.

Nitric oxide (NO) is derived from endothelial nitric oxide synthase and has been reported to have beneficial effects on vascular functions [11,12]. NO stimulates arterial and venous vasorelaxation via increasing the cyclic guanosine monophosphate and inhibits arterial smooth muscle cell (SMC) migration and proliferation [13]. Tong et al. investigated SMCs cultured from explants of venous tissue obtained during fistula formation and reported that smooth muscle responsiveness to nitric oxide was associated with fistula maturation results [14].

Matrix metalloproteinases (MMP) are important in the process of AVF maturation $[15,16]$. The MMP is known to disrupt the layered structure of the media of the artery and promote vasodilation $[17,18]$. Chan et al. found that a high flow rate in the fistula vein affects the expression of MMPs and type 4 tissue inhibitor of metalloproteinases (TIMP-4), resulting in the remodeling or maturation of the AVF in the experimental model [16]. The physical and biological factors that develop on AVF creation affect endothelial and smooth muscle cell function, and extracellular matrix remodeling [10]. Remodeling of AVF causes a progressive increase in vessel diameter, and excessive increased blood flow leads to HFA.

Kong et al. attempted to identify the molecular mechanism which affects venous remodeling after AVF creation [19]. This report screened and identified the differentially expressed genes (DEGs) that may be associated with venous remodeling after AVF creation, and stated that both INHBA and NR4A2 expression might play an important role.

In secondary AVF creation with enlarged artery and vein, a large anastomosis size causes HFA immediately after surgery. In the long term, HFA is induced by the enlargement of venous diameter due to repeated punctures or the formation of venous aneurysms [20].

On the other hand, not all of these cases develop into HFA after AVF creation. Recent studies reported the incidence of AVF primary failure due to non-maturation ranges between $20 \%$ and $60 \%$ [21-24]. Two major etiologies of AVF maturation disorders are excessive neointimal hyperplasia $(\mathrm{NH})$ and inadequate luminal dilation of veins [25,26]. $\mathrm{NH}$ is a result of vascular smooth muscle cells and fibroblasts migrating and proliferating from the vessel media into the intima, and usually occurs on the venous side of anostosis $[25,27]$. Also, diabetes mellitus may protect patients from developing HFA because arterial remodeling is hampered due to atherosclerosis [28].

\section{Condition of High Flow Access and High-Output Heart Failure}

High flow access (HFA) is a condition in which hemodynamics is affected by a flow rate that is larger than the blood flow required for hemodialysis. HFA has been defined as a flow of $>1.5-2.0 \mathrm{~L} / \mathrm{min}$ [29] or one where the access flow is $>20 \%$ of the cardiac output $[4,30]$. The effects of AVF creation on the access limb and cardiovascular system are well known. As a result of the left-to-right extracardiac shunt, the cardiac output increases by $10 \%$ to $20 \%$ [31,32], and the left ventricular mass increases by $12.7 \%$ [33], causing left ventricular remodeling [1]. HFA causes venous hypertension, steal syndrome, heart failure, and arrhythmia due to the increased cardiac load and systemic steal phenomenon [34-36]. High-output heart failure due to HFA causes shortness of breath, palpitations, lower limb edema, a loss of appetite, orthopnea, and dyspnea on effort [4]. HFA becomes more severe in the presence of organic diseases such as ischemic heart disease, cardiomyopathy, valvular disease, myocarditis, and arrhythmia [4]. A prospective study involving 1254 end-stage renal disease (ESRD) patients showed that having a left ventricular ejection fraction (LVEF) of lower than 30\% at the start of HD was associated with a nine-fold greater risk of cardiovascular death [37]. In the presence of HFA, high-output heart failure may occur, so a flow reduction is suggested [29].

In HFA patients with high-output heart failure, cardiac output and pulmonary artery pressure were shown to decrease after surgical closure of the access. Additionally, the 
patients' cardiac performance improved [38]. This indicates that it is important to close accesses at the right time, and that closure can improve cardiac function and reduce highoutput heart failure. Improvements in cardiac function by reducing the flow volume of HFA patients with high-output heart failure have also been reported [39]. Twelve acute congestive heart failure patients with a flow volume of $>2 \mathrm{~L} /$ min requiring hospitalization underwent flow reduction by banding and were followed up for six months. Flow reduction was associated with decreased LVMI and pulmonary artery pressures. Additionally, a reduction in the risk of hospitalization and an improvement in New York Heart Association (NYHA) heart failure stage was reported.

It is not yet clear whether it is beneficial to reduce blood flow in HFA patients without symptoms of heart failure. It has been reported that the mean left ventricular mass index (LVMI) improved from 135 to $120 \mathrm{~g} / \mathrm{m}^{2}$ at $4-5$ months after the closure of access in 19 patients without heart failure. It is expected that the LVMI would not change if access was not closed [40]. It was been reported that, after renal transplantation, the LVMI decreased, and left ventricular hypertrophy improved at 1 month and 21 months after AVF closure [40]. Another study indicated that, in renal transplant patients, AVF closure was associated with decreases in both eccentric and concentric hypertrophy and a trend towards normalization of the cardiac structure was shown [41].

Emma Aitken et al. investigated the effect of AVF closure on hemodynamics in $100 \mathrm{pa}-$ tients undergoing hemodialysis with AVF in a cohort study [42]. The AVF was occluded by digital pressure just proximal to the anastomotic site for $15 \mathrm{~min}$, and hemodynamic parameters were measured before and after $15 \mathrm{~min}$ with the AVF occluded. Patients were also followed up prospectively for one year, and any subsequent major adverse cardiovascular events (MACE) or mortality events were recorded. A total of $29 \%$ of the patients had a flow volume of $>1500 \mathrm{~mL} / \mathrm{min}$, and $15 \%$ of the patients had a flow volume/CO of $>20 \%$. A total of 20 patients had MACE in the year after this measurement was obtained, and eight deaths occurred. The mean flow volume was lower in patients who went on to develop MACE in the following year than those who did not. The cardiac index before AVF occlusion was lower in patients who subsequently developed MACE than in those who did not. It was demonstrated that many patients do not develop high-output cardiac failure even in the presence of high CO. A high CO state was more likely to occur in patients with a high flow volume and resolved upon occlusion of the fistula. The relationships among $\mathrm{CO}$, flow volume, and cardiovascular events are complex.

\section{Venous Hypertension}

The pathophysiology of venous hypertension results from venous stagnation in the access limb due to an imbalance between access flow and the outflow resulting from venous vascular resistance. Treatment of this condition requires access flow reduction, venous outflow vascular resistance attenuation, or both [43]. Side-to-side anastomosis or elbow outflow venous tract insufficiency can cause venous hypertension in the forearm. Central venous stenosis, or cephalic arch stenosis, causes venous hypertension throughout the upper limbs. Having a history of central venous catheter placement is a risk factor for this condition. Venous stasis due to impaired venous return progresses to edema, bluish discoloration, pigmentation of the skin, pain, skin necrosis, and neuralgias [44]. In addition to PTA, surgical treatments such as venous ligation, venous transposition, and graft interposition are used for the treatment of venous hypertension in the forearm [45]. For central venous lesions or cephalic arch stenosis, outflow grafting to the jugular vein [46] or cephalic vein transposition [47] can also be performed, but surgical intervention is often difficult and PTA remains the basis of treatment [48].

\section{Dialysis Access Steal Syndrome (DASS)}

DASS results from tissue ischemia due to an imbalance between access flow and arterial vascular resistance, and treatment requires the suppression of shunt blood flow and/or reconstruction of the arterial blood circulation. Therefore, a reduction in blood flow 
is a key procedure for treating venous hypertension and DASS associated with HFA [43,49]. The physiological or asymptomatic steal phenomenon is found in up to $90 \%$ of cases of dialysis access, while clinically significant DASS requiring surgical intervention is found in $1-8 \%$ of cases [50]. Risk factors associated with DASS include smoking, diabetes, PAD (peripheral vascular disease), female gender, age, hypertension, and CAD (coronary artery disease) [50-52]. DASS treatment options are either proximalization of the arterial inflow (PAI), distal revascularization and interval ligation (DRIL), or distal revascularization (DR) alone. High flow AVA has various definitions including values of $>1500$ or $2000 \mathrm{~mL} / \mathrm{min}$ [53]. DASS treatment options for HFA should include a flow reduction procedure.

\section{Flow Reduction Procedures}

The fluid dynamics of blood, a viscous fluid, can be approximated by Hagen-Poiseuille's law $\mathrm{Q}=\pi \mathrm{r} 4 \Delta \mathrm{P} /(8 \eta \mathrm{L})$. The flow rate $\mathrm{Q}$ flowing through a circular tube with radius $\mathrm{r}$ and length $\mathrm{L}$ is proportional to the fourth power of the radius and the pressure difference $\Delta \mathrm{P}$ at both ends of the circular tube and inversely proportional to the length $\mathrm{L}$ and viscosity $\eta$. During blood flow reduction surgery, reduction of blood vessel diameters affects the blood flow at the fourth power level, and reducing their lengths only affects the first power level. While radical treatment for HFA involves the closure of the access, a flow reduction procedure is required to preserve the access.

HFA is recognized as a well-developed access due to its good access sound, thrill, and vessel diameter; also, HFA probably has good patency if not intervened with by flow reduction (Figure 1A). Therefore, blood flow reduction procedures need to minimize disadvantages such as access thrombosis, insufficient blood flow, aneurysm formation, and infection by therapeutic intervention, while at the same time achieving symptom improvement and long-term patency. Moreover, the surgical procedure used to treat HFA must be highly reproducible and simple. Various surgical methods are currently performed to treat high flow accesses, such as banding [4,54-57] (Figure 1B,C), fistula plication $[4,58]$ (Figure 1D), proximal radial artery ligation (PRAL) [59], graft interposition [60] (Figure 1E), revision using distal inflow (RUDI) [61], and the graft inclusion technique [43] (Figure 1F).

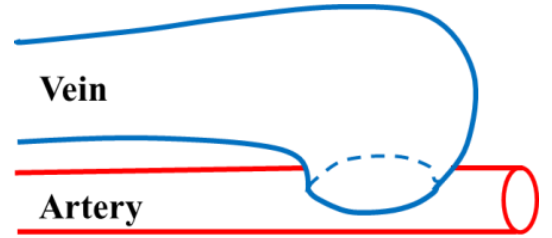

(A)

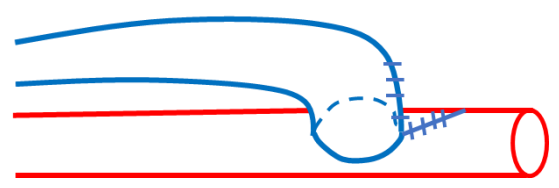

(D)

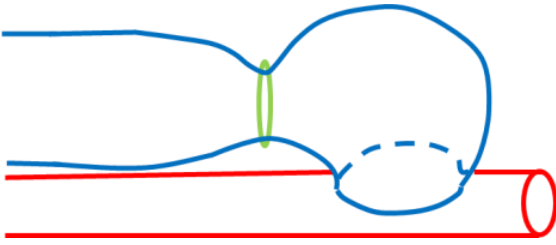

(B)

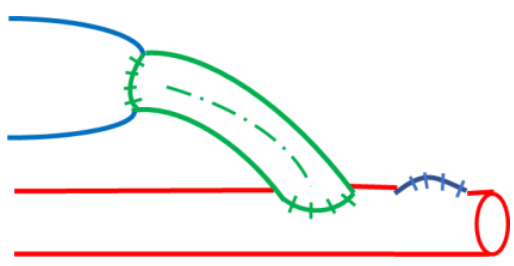

(E)

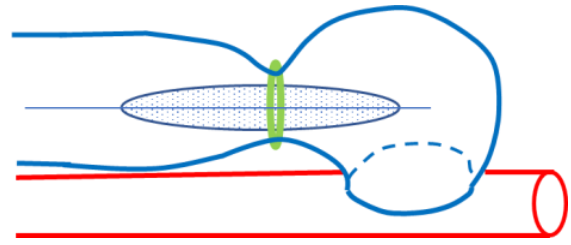

(C)

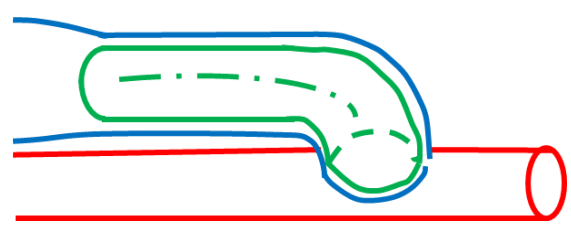

(F)

Figure 1. Surgical flow reduction procedures are used to treat high-flow accesses. (A) Schema showing an HFA due to an enlarged anastomotic site and veins. (B) Venous banding is a method used to create stenosis in an enlarged vein using a ligature or a strip of graft. (C) MILLER banding involves ligation of the enlarged vein using an inserted PTA balloon. (D) Anastoplasty involves reducing the size of the anastomotic site under direct vision. (E) Graft interposition involves closing the previous anastomosis and creating a new AVG with a small-diameter graft. (F) Graft inclusion, technique in which a $4 \mathrm{~mm}$ diameter PTFE graft is sewn to an expanded anastomotic site, and a length of about $4 \mathrm{~cm}$ is inserted into the blood vessel. 


\section{Banding}

Banding is a surgical procedure that is often used to treat HFA. It involves the creation of a stenotic part of the outflow tract vein with a thread at 1-2 points or wrapping a PTFE band around the blood vessel to make a stenotic part (Figures 1B and 2). Venous banding was the first flow limitation technique to be described [55], and banding on the venous side is a simple operation involving less surgical invasion; however, it is difficult to control blood flow by blind methods such as banding without intraoperative flow monitoring, and early occlusion can occur due to overtightening, insufficient suppression, or relapse of excessive blood flow. Surgical results for this technique have been poor due to the high incidence of thrombosis [52,62]. A high recurrence rate has also been reported. Banding was performed for $50 \mathrm{HFA}$ patients; however, a relapse of recurrent high flow $(2 \mathrm{~L} / \mathrm{min})$ occurred in $52 \%$ of patients during the one-year follow-up period [28]. Banding seems to be in the category of less surgical invasion compared with other blood flow suppression methods, but banding does not have the indicators required to reduce the blood flow to the desired level or improve symptoms [63]. In previous reports, a high incidence of thrombus formation rate was reported with $19-90 \%$ of cases associated with banding procedure $[51,52,58,64]$. Kanno et al. reported the use of three different blood flow reduction procedures for 74 HFA patients: proximal artery banding with distal artery ligation (A-ban with A-lig: 12 cases), venous banding (V-ban: 37 cases), and fistula anastoplasty (Ana: 25 cases). A-ban with A-lig involves banding of the proximal artery using an expanded polytetrafluoroethylene (ePTFE) band and ligation of the distal artery. V-ban involves banding of the venous side of the anastomosis site with an ePTFE band. Ana involves making an incision near the AVF anastomotic site. The anastomotic site is placed under direct vision, and then an anastomotic site is formed by continuous running suture at the anastomotic site (Figure 1D). The changes in flow volume for the surgical procedures before and after surgery were 1423 and $600 \mathrm{~mL} / \mathrm{min}$ (A-ban with A-lig), 1266 and $501 \mathrm{~mL} / \mathrm{min}$ (V-ban), and 1333 and $614 \mathrm{~mL} / \mathrm{min}$ (Ana), respectively. A-ban with A-lig achieved reliable blood flow suppression, was associated with less risk of HFA recurrence and obstruction and was found to be suitable for AVF close to the wrist. V-ba is technically easy and can be applied to various HFAs, but it may be better to avoid it due to its associations with calcifications, aneurysms, and cubital fistulas. Ana is recommended because it provides reliable blood flow reduction for all types of fistulas and reduces the risks of relapse and obstruction [4]. Miller et al. reported the use of a modified banding technique in 16 patients. This procedure, named MILLER banding (Minimally Invasive Limited Ligation Endoluminal-assisted Revision), requires a 1-2 $\mathrm{cm}$ skin incision for a ligature and a 4 or $5 \mathrm{~mm}$ diameter PTA balloon to achieve the desired reduction in inflow size [63] (Figure 1C). In 2010, Miller published a review of 183 patients who underwent the MILLER procedure [65]. In this report, there were 114 patients with a true steal and 69 patients with signs/symptoms of high flow access. The most commonly used PTA balloon size was $4 \mathrm{~mm}$ for AVFs and $3 \mathrm{~mm}$ for grafts [66]. Shintaku et al. conducted a retrospective review and presented modifications to the MILLER procedure [67]. In this report, blood flow measurement using Doppler ultrasonography was performed and a finger pulse oximeter was used for intraoperative monitoring during surgery for seven HFA patients and five DASS patients. The mean flow volume was reduced from 2043 to $1248 \mathrm{~mL} / \mathrm{min}$ in HFA patients, and the flow reduction rate was 39\%. In this series, the diameter of the PTA balloon ranged from 3 to $6 \mathrm{~mm}$, and the most commonly used diameter was $3.5 \mathrm{~mm}$. In the DASS patients, the diameter of the PTA balloon ranged from 2 to $4 \mathrm{~mm}$, and the flow reduction rate was controlled to be lower $[66,67]$. 


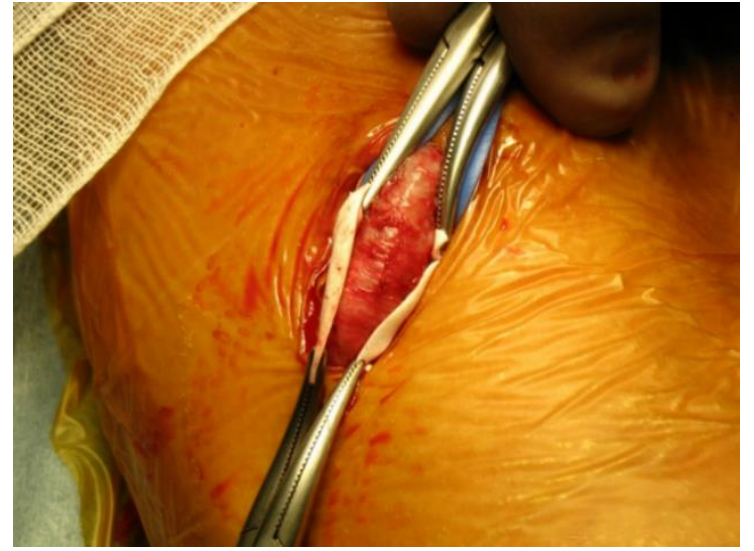

(A)

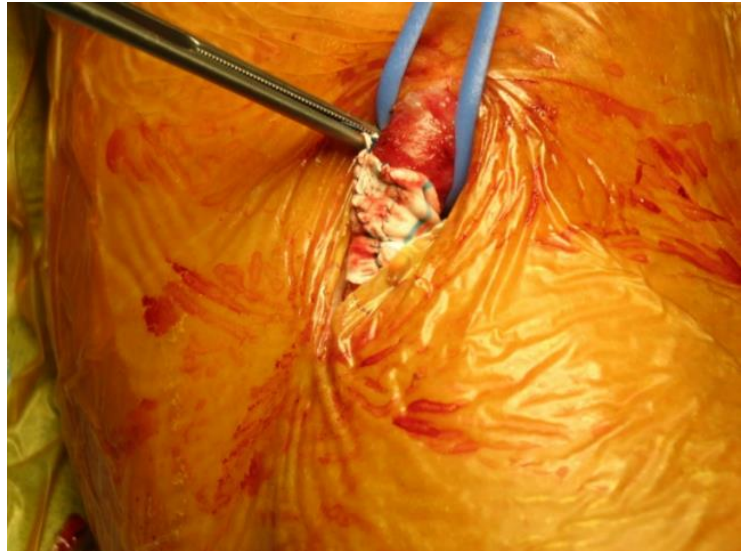

(B)

Figure 2. Banding. (A) Venous banding is a method of creating stenosis in an enlarged vein using a graft strip. (B) Flow reduction obtained by stitching graft strip wrapped around the enlarged vein.

\section{Fistula Plication}

The fistula plication technique is a method of surgically reshaping an enlarged anastomotic site and its vicinity [68]. Banding involves wrapping a band from the outside of the vessel to narrow the vessel, while fistula plication reduces the size of the anastomotic site itself under direct vision. Therefore, fistula plication is a theoretical blood flow suppression method. There is no pressure increase near the anastomotic site, a phenomenon that is often seen in banding. The technique can be applied to cases where banding is difficult due to advanced arteriovenous dilation, and it has been stated that an outstanding technique is required to sew the anastomotic site under direct vision of the lumen [4] (Figures 1D and 3).

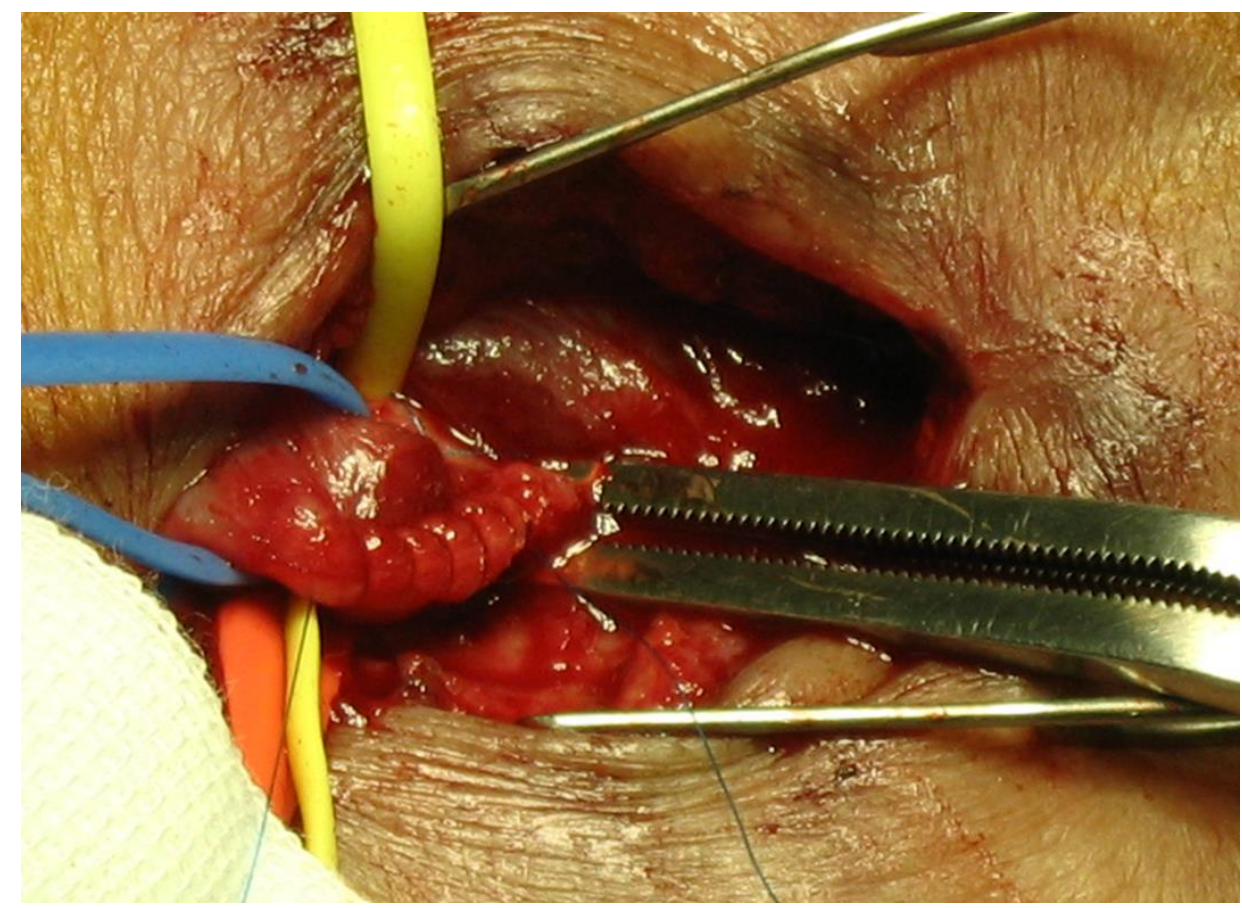

Figure 3. Plication of an AVF fistula. Plication of the enlarged fistula and vein near the site of anastomosis.

Banding and plication are both procedures that rely on increasing the resistance to access flow, thereby increasing peripheral arterial perfusion [64,69]. 


\section{Graft Interposition}

For graft interposition [70] and revision using distal inflow (RUDI) [61] and replacement with a graft, blood flow can be easily suppressed, and a reliable level of blood flow can be maintained by using small-diameter grafts. Interposition using a graft with a diameter of $5 \mathrm{~mm}$ and an average length of $5 \mathrm{~cm}$ has shown good results with a blood flow suppression rate of $52 \%$, a three-year primary patency rate of $58 \%$, and a secondary patency rate of $71 \%$ [70]. The theoretical background of graft interposition is that part of the HFA is replaced by a small-diameter graft. Since the graft diameter does not expand, blood flow is suppressed (Figures 1E and 4).

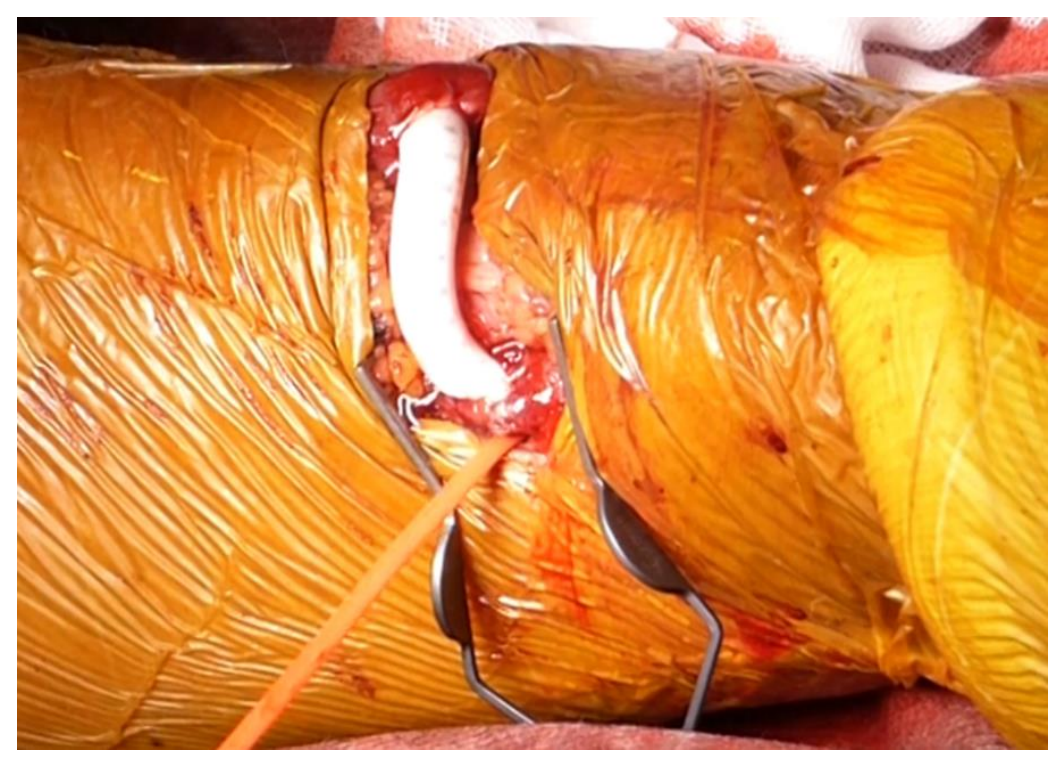

Figure 4. Graft interposition. The previous anastomosis is closed and a new AVG with a smalldiameter graft is created.

\section{Graft Inclusion Technique}

The graft inclusion technique (GIT) is a surgical technique in which a PTFE graft with a $4 \mathrm{~mm}$ diameter is sewn to an expanded anastomotic site, and a length of about $4 \mathrm{~cm}$ is inserted into the venous side of the fistula to reduce the flow volume [43] (Figure 1F). GIT is a simple procedure in which the arterial side is not detached; only the venous side is detached. Since blood flow is suppressed by a small-diameter PTFE graft, an advantage is that intraoperative blood flow measurement and blood flow regulation, which are required for venous and arterial banding, are not required. Since this type of surgery is standardized, the reproducibility of the technique is good, and it is simpler than surgical procedures that require skillful techniques, such as anastomosis plication. It can be performed on the forearm or elbow, regardless of the anastomosis site of the AVF, and since it can be performed with a short graft of about $3-4 \mathrm{~cm}$, the surgical site does not easily interfere with the existing puncture site, so access, including that of the puncture site, can be preserved. Since the PTFE graft is completely contained in the autologous vein and no part of the graft is exposed, the rates of seroma, edema, and infection are comparable with those of graft interposition, in which the graft is directly embedded under the skin using graft methods such as RUDI. This method is expected to reduce the disadvantages associated with the use of grafts (Figure 5). The primary patency rate in GIT is $28.5 \%$ for five years for the entire access circuit, while the primary patency rate for GIT alone is $31.8 \%$ for five years, the secondary patency rate is $67.7 \%$ for five years, and the blood flow suppression rate during the remote period is $39.6 \%$ [43]. It has been reported that this technique avoids thrombosis obstruction, and has a stable blood flow suppression effect and patency for a long period of time [43]. GIT surgery videos are available in the online Supplementary Materials. 


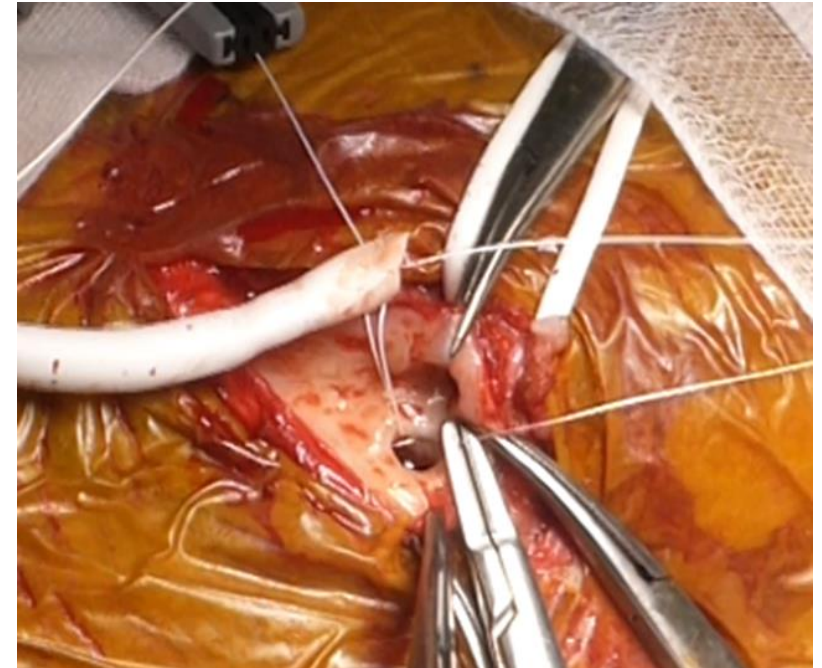

(A)

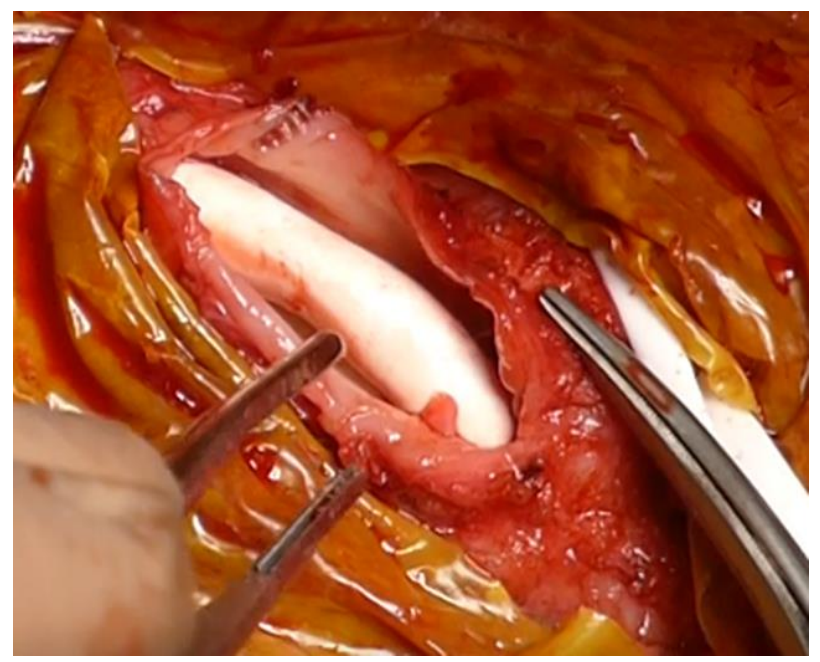

(C)

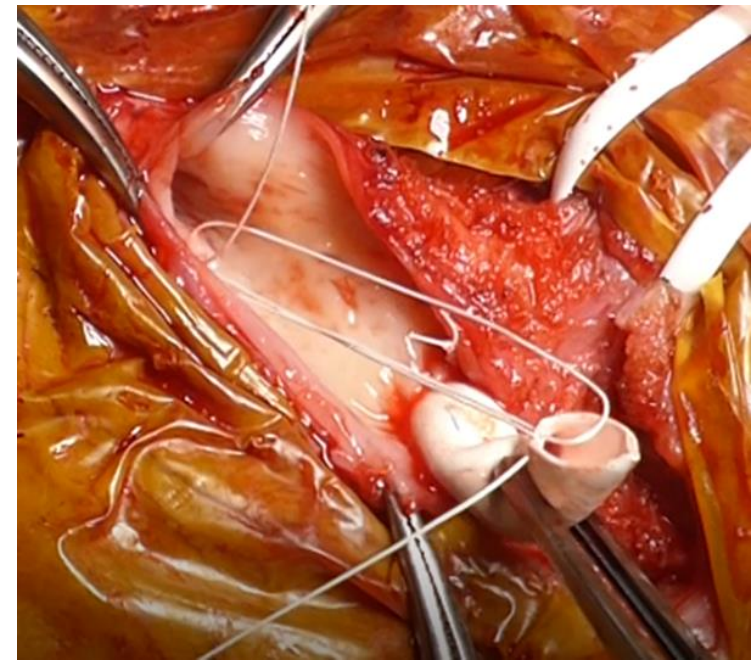

(B)

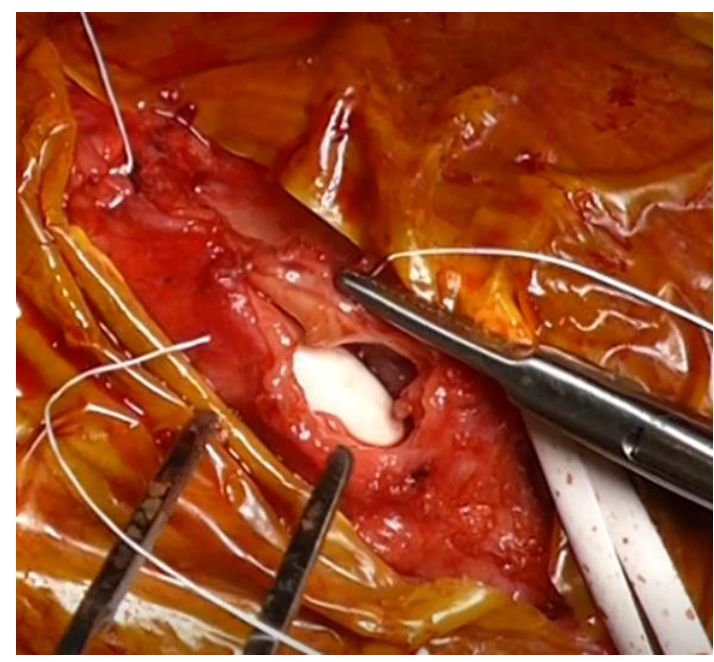

(D)

Figure 5. Graft inclusion technique. (A) A 4 mm diameter PTFE graft is sewn to the enlarged AVF anastomosis site, and the anastomotic size is reduced to the graft diameter. (B) The other end of the graft is interpolated and sutured to the outflow tract vein in the same manner. A 3 to $4 \mathrm{~cm}$ long PTFE graft is inserted from the anastomotic site to the outflow tract vein. (C) By excising the surplus vessel wall, the aneurysm or dilated anastomotic site is excised. (D) The graft is included by completely wrapping the venous wall. Hemostasis at the anastomotic site becomes easier.

\section{Conclusions}

Cardiovascular disease is the most common cause of death for chronic dialysis patients. HFA has a considerable effect on cardiovascular disease, and high-output heart failure affects prognosis. In the treatment of high output heart failure, venous hypertension, and DASS caused by HFA, it is important to make an accurate diagnosis and select the most appropriate procedures to treat the pathological condition. Various surgical methods are currently performed to treat high-flow access. It is important to minimize the disadvantages of flow reduction procedures while at the same time achieving symptom improvement and long-term patency. We believe that we should aim to preserve VA by selecting treatments that are suitable for the pathophysiology of HFA, rather than simply closing and abandoning cases of VA that have developed into HFA. 
Supplementary Materials: The following are available online at https://www.mdpi.com/article/10 .3390/kidneydial1010007/s1, Video S1: Graft inclusion technique is available on the online supplement.

Author Contributions: Conceptualization, methodology, writing-original draft preparation, writing-review and editing, T.N. and Y.M. Both authors have read and agreed to the published version of the manuscript.

Funding: This research received no external funding.

Institutional Review Board Statement: Not applicable.

Informed Consent Statement: Informed consent was obtained from all subjects involved in the study.

Conflicts of Interest: The authors declare no conflict of interest.

\section{References}

1. MacRae, J.M.; Levin, A.; Belenkie, I. The cardiovascular effects of arteriovenous fistulas in chronic kidney disease: A cause for concern? Semin. Dial. 2006, 19, 349-352. [CrossRef]

2. Basile, C.; Lomonte, C. Pro: The arteriovenous fistula is a blessing of God. Nephrol. Dial. Transplant. Off. Publ. Eur. Dial. Transpl. Assoc. Eur. Ren. Assoc. 2012, 27, 3752-3756. [CrossRef]

3. Roca-Tey, R. Permanent arteriovenous fistula or catheter dialysis for heart failure patients. J. Vasc. Access 2016, 17, S23-S29. [CrossRef]

4. Kanno, T.; Kamijo, Y.; Hashimoto, K.; Kanno, Y. Outcomes of blood flow suppression methods of treating high flow access in hemodialysis patients with arteriovenous fistula. J. Vasc. Access 2015, 16 (Suppl. S1), S28-S33. [CrossRef] [PubMed]

5. Torreggiani, M.; Scaramuzzi, M.L.; Manini, A.; Castoldi, F.; Serpieri, N.; Maggi, N.; Sileno, G.; Migotto, C.; Esposito, V.; Montagna, F.; et al. Hemodialysis vascular access: Everything you always wanted to know about it (but were afraid to ask). J. Nephrol. 2013, 26, 836-847. [CrossRef] [PubMed]

6. Nakamura, T.; Suemitsu, K.; Nakamura, J. Superficialization of brachial artery as effective alternative vascular access. J. Vasc. Surg. 2014, 59, 1385-1392. [CrossRef] [PubMed]

7. Brescia, M.J.; Cimino, J.E.; Appell, K.; Hurwich, B.J. Chronic hemodialysis using venipuncture and a surgically created arteriovenous fistula. N. Engl. J. Med. 1966, 275, 1089-1092. [CrossRef] [PubMed]

8. Dixon, B.S. Why don't fistulas mature? Kidney Int. 2006, 70, 1413-1422. [CrossRef]

9. Dammers, R.; Tordoir, J.H.M.; Welten, R.J.T.H.J.; Kitslaar, P.J.E.H.M.; Hoeks, A.P.G. The effect of chronic flow changes on brachial artery diameter and shear stress in arteriovenous fistulas for hemodialysis. Int. J. Artif. Organs 2002, 25, 124-128. [CrossRef] [PubMed]

10. Dammers, R.; Tordoir, J.H.M.; Kooman, J.P.; Welten, R.J.T.J.; Hameleers, J.M.M.; Kitslaar, P.J.E.H.M.; Hoeks, A.P.G. The effect of flow changes on the arterial system proximal to an arteriovenous fistula for hemodialysis. Ultrasound Med. Biol. 2005, 31, 1327-1333. [CrossRef]

11. Roumeliotis, S.; Mallamaci, F.; Zoccali, C. Endothelial Dysfunction in Chronic Kidney Disease, from Biology to Clinical Outcomes: A 2020 Update. J. Clin. Med. 2020, 9, 2359-2386. [CrossRef]

12. Huynh, N.N.; Chin-Dusting, J. Amino acids, arginase and nitric oxide in vascular health. Clin. Exp. Pharmacol. Physiol. 2006, 33, 1-8. [CrossRef]

13. Vallance, P.; Hingorani, A. Endothelial nitric oxide in humans in health and disease. Int. J. Exp. Pathol. 1999, 80, 291-303. [CrossRef] [PubMed]

14. Tong, X.; Hou, X.; Wason, C.; Kopel, T.; Cohen, R.A.; Dember, L.M. Smooth Muscle Nitric Oxide Responsiveness and Clinical Maturation of Hemodialysis Arteriovenous Fistulae. Am. J. Pathol. 2017, 187, 2095-2101. [CrossRef] [PubMed]

15. Berceli, S.A.; Jiang, Z.; Klingman, N.V.; Schultz, G.S.; Ozaki, C.K. Early differential MMP-2 and -9 dynamics during flow-induced arterial and vein graft adaptations. J. Surg. Res. 2006, 134, 327-334. [CrossRef] [PubMed]

16. Chan, C.-Y.; Chen, Y.-S.; Ma, M.-C.; Chen, C.-F. Remodeling of experimental arteriovenous fistula with increased matrix metalloproteinase expression in rats. J. Vasc. Surg. 2007, 45, 804-811. [CrossRef]

17. Achneck, H.E.; Sileshi, B.; Li, M.; Partington, E.J.; Peterson, D.A.; Lawson, J.H. Surgical aspects and biological considerations of arteriovenous fistula placement. Semin. Dial. 2010, 23, 25-33. [CrossRef]

18. Ben Driss, A.; Benessiano, J.; Poitevin, P.; Levy, B.I.; Michel, J.B. Arterial expansive remodeling induced by high flow rates. Am. J. Physiol. 1997, 272, H851-H858. [CrossRef]

19. Jie, K.; Feng, W.; Boxiang, Z.; Maofeng, G.; Jianbin, Z.; Zhaoxuan, L.; Yangyi, Z.; Liang, C.; Haobo, S.; Wensheng, L.; et al. Identification of Pathways and Key Genes in Venous Remodeling After Arteriovenous Fistula by Bioinformatics Analysis. Front. Physiol. 2020, 11, 565240. [CrossRef] 
20. Panagrosso, M.; Bracale, U.M.; Del Guercio, L.; Viscardi, A.; Peluso, A.; Dinoto, E. Case report of a large cephalic vein aneurysm inducing heart failure in a renal transplant patient with radio-cephalic fistula for haemodialysis. Int. J. Surg. Case Rep. 2020, 77S, S162-S165. [CrossRef]

21. Dember, L.M.; Imrey, P.B.; Beck, G.J.; Cheung, A.K.; Himmelfarb, J.; Huber, T.S.; Kusek, J.W.; Roy-Chaudhury, P.; Vazquez, M.A.; Alpers, C.E.; et al. Objectives and design of the hemodialysis fistula maturation study. Am. J. Kidney Dis. Off. J. Natl. Kidney Found. 2014, 63, 104-112. [CrossRef]

22. Allon, M.; Lok, C.E. Dialysis fistula or graft: The role for randomized clinical trials. Clin. J. Am. Soc. Nephrol. 2010, 5, $2348-2354$. [CrossRef]

23. Dember, L.M.; Beck, G.J.; Allon, M.; Delmez, J.A.; Dixon, B.S.; Greenberg, A.; Himmelfarb, J.; Vazquez, M.A.; Gassman, J.J.; Greene, T.; et al. Effect of clopidogrel on early failure of arteriovenous fistulas for hemodialysis: A randomized controlled trial. JAMA 2008, 299, 2164-2171. [CrossRef] [PubMed]

24. Huijbregts, H.J.T.; Bots, M.L.; Wittens, C.H.A.; Schrama, Y.C.; Moll, F.L.; Blankestijn, P.J. Hemodialysis arteriovenous fistula patency revisited: Results of a prospective, multicenter initiative. Clin. J. Am. Soc. Nephrol. 2008, 3, 714-719. [CrossRef]

25. Roy-Chaudhury, P.; Arend, L.; Zhang, J.; Krishnamoorthy, M.; Wang, Y.; Banerjee, R.; Samaha, A.; Munda, R. Neointimal hyperplasia in early arteriovenous fistula failure. Am. J. Kidney Dis. Off. J. Natl. Kidney Found. 2007, 50, 782-790. [CrossRef] [PubMed]

26. Corpataux, J.-M.; Haesler, E.; Silacci, P.; Ris, H.B.; Hayoz, D. Low-pressure environment and remodelling of the forearm vein in Brescia-Cimino haemodialysis access. Nephrol. Dial. Transplant. Off. Publ. Eur. Dial. Transpl. Assoc. Eur. Ren. Assoc. 2002, 17, 1057-1062. [CrossRef] [PubMed]

27. Roy-Chaudhury, P.; Sukhatme, V.P.; Cheung, A.K. Hemodialysis vascular access dysfunction: A cellular and molecular viewpoint. J. Am. Soc. Nephrol. 2006, 17, 1112-1127. [CrossRef]

28. Vaes, R.H.D.; Wouda, R.; van Loon, M.; van Hoek, F.; Tordoir, J.H.; Scheltinga, M.R. Effectiveness of surgical banding for high flow in brachial artery-based hemodialysis vascular access. J. Vasc. Surg. 2015, 61, 762-766. [CrossRef] [PubMed]

29. Basile, C.; Lomonte, C.; Vernaglione, L.; Casucci, F.; Antonelli, M.; Losurdo, N. The relationship between the flow of arteriovenous fistula and cardiac output in haemodialysis patients. Nephrol. Dial. Transpl. 2008, 23, 282-287. [CrossRef] [PubMed]

30. Sequeira, A.; Tan, T.-W. Complications of a High-flow Access and Its Management. Semin. Dial. 2015, 28, 533-543. [CrossRef]

31. Korsheed, S.; Eldehni, M.T.; John, S.G.; Fluck, R.J.; McIntyre, C.W. Effects of arteriovenous fistula formation on arterial stiffness and cardiovascular performance and function. Nephrol. Dial. Transplant. Off. Publ. Eur. Dial. Transpl. Assoc. Eur. Ren. Assoc. 2011, 26, 3296-3302. [CrossRef]

32. Ori, Y.; Korzets, A.; Katz, M.; Erman, A.; Weinstein, T.; Malachi, T.; Gafter, U. The contribution of an arteriovenous access for hemodialysis to left ventricular hypertrophy. Am. J. Kidney Dis. Off. J. Natl. Kidney Found. 2002, 40, 745-752. [CrossRef]

33. Dundon, B.K.; Torpey, K.; Nelson, A.J.; Wong, D.T.; Duncan, R.F.; Meredith, I.T.; Faull, R.J.; Worthley, S.G.; Worthley, M.I. The deleterious effects of arteriovenous fistula-creation on the cardiovascular system: A longitudinal magnetic resonance imaging study. Int. J. Nephrol. Renovasc. Dis. 2014, 7, 337-345. [PubMed]

34. McIntyre, C.W. Effects of hemodialysis on cardiac function. Kidney Int. 2009, 76, 371-375. [CrossRef] [PubMed]

35. Derthoo, D.; Belmans, A.; Claes, K.; Bammens, B.; Ciarka, A.; Droogné, W.; Vanhaecke, J.; Van Cleemput, J.; Janssens, S. Survival and heart failure therapy in chronic dialysis patients with heart failure and reduced left ventricular ejection fraction: An observational retrospective study. Acta Cardiol. 2013, 68, 51-57. [CrossRef] [PubMed]

36. Duque, J.C.; Gomez, C.; Tabbara, M.; Alfonso, C.E.; Li, X.; Vazquez-Padron, R.I.; Asif, A.; Lenz, O.; Briones, P.L.; Salman, L.H. The impact of arteriovenous fistulae on the myocardium: The impact of creation and ligation in the transplant era. Semin. Dial. 2015, 28, 305-310. [CrossRef]

37. Yamada, S.; Ishii, H.; Takahashi, H.; Aoyama, T.; Morita, Y.; Kasuga, H.; Kimura, K.; Ito, Y.; Takahashi, R.; Toriyama, T.; et al. Prognostic value of reduced left ventricular ejection fraction at start of hemodialysis therapy on cardiovascular and all-cause mortality in end-stage renal disease patients. Clin. J. Am. Soc. Nephrol. 2010, 5, 1793-1798. [CrossRef]

38. Voorzaat, B.M.; van Schaik, J.; Siebelink, H.-M.J.; Tordoir, J.H.; Rotmans, J.I. The pros and cons of preserving a functioning arteriovenous fistula after kidney transplantation. J. Vasc. Access 2016, 17 (Suppl. S1), S16-S22. [CrossRef]

39. Balamuthusamy, S.; Jalandhara, N.; Subramanian, A.; Mohanaselvan, A. Flow reduction in high-flow arteriovenous fistulas improve cardiovascular parameters and decreases need for hospitalization. Hemodial. Int. 2016, 20, 362-368. [CrossRef]

40. Van Duijnhoven, E.C.; Cheriex, E.C.; Tordoir, J.H.; Kooman, J.P.; van Hooff, J.P. Effect of closure of the arteriovenous fistula on left ventricular dimensions in renal transplant patients. Nephrol. Dial. Transplant. Off. Publ. Eur. Dial. Transpl. Assoc. Eur. Ren. Assoc. 2001, 16, 368-372. [CrossRef]

41. Movilli, E.; Viola, B.F.; Brunori, G.; Gaggia, P.; Camerini, C.; Zubani, R.; Berlinghieri, N.; Cancarini, G. Long-term effects of arteriovenous fistula closure on echocardiographic functional and structural findings in hemodialysis patients: A prospective study. Am. J. Kidney Dis. Off. J. Natl. Kidney Found. 2010, 55, 682-689. [CrossRef]

42. Aitken, E.; Kerr, D.; Geddes, C.; Berry, C.; Kingsmore, D. Cardiovascular changes occurring with occlusion of a mature arteriovenous fistula. J. Vasc. Access 2015, 16, 459-466. [CrossRef]

43. Nojima, T.; Motomiya, Y. Graft Inclusion Technique: A New Flow Reduction Procedure for High Flow Arteriovenous Fistulae. Ann. Vasc. Dis. 2018, 11, 202-209. [CrossRef] 
44. Neville, R.F.; Abularrage, C.J.; White, P.W.; Sidawy, A.N. Venous hypertension associated with arteriovenous hemodialysis access. Semin. Vasc. Surg. 2004, 17, 50-56. [CrossRef]

45. Georgakarakos, E.I.; Kapoulas, K.C.; Georgiadis, G.S.; Tsangaris, A.S.; Nikolopoulos, E.S.; Lazarides, M.K. An overview of the hemodynamic aspects of the blood flow in the venous outflow tract of the arteriovenous fistula. J. Vasc. Access 2012, 13, 271-278. [CrossRef]

46. Kim, M.J.; Yun, S.; Song, D.; Cho, S.W.; Goo, D.E.; Kim, Y.J.; Choi, D. Alternative venous outflow by brachial to jugular vein vascular access for hemodialysis in the exhausted upper extremities. J. Vasc. Access 2015, 16, 269-274. [CrossRef]

47. Henry, J.C.; Sachdev, U.; Hager, E.; Dillavou, E.; Yuo, T.; Makaroun, M.; Leers, S.A. Cephalic vein transposition is a durable approach to managing cephalic arch stenosis. J. Vasc. Access 2017. [CrossRef]

48. Sivananthan, G.; Menashe, L.; Halin, N.J. Cephalic arch stenosis in dialysis patients: Review of clinical relevance, anatomy, current theories on etiology and management. J. Vasc. Access 2014, 15, 157-162. [CrossRef] [PubMed]

49. Mohamed, A.S.; Peden, E.K. Dialysis-associated steal syndrome (DASS). J. Vasc. Access 2017, 18, 68-73. [CrossRef] [PubMed]

50. Beathard, G.A.; Spergel, L.M. Hand ischemia associated with dialysis vascular access: An individualized access flow-based approach to therapy. Semin. Dial. 2013, 26, 287-314. [CrossRef] [PubMed]

51. Gupta, N.; Yuo, T.H.; Konig, G., 4th; Dillavou, E.; Leers, S.A.; Chaer, R.A.; Cho, J.S.; Makaroun, M.S. Treatment strategies of arterial steal after arteriovenous access. J. Vasc. Surg. 2011, 54, 162-167. [CrossRef]

52. DeCaprio, J.D.; Valentine, R.J.; Kakish, H.B.; Awad, R.; Hagino, R.T.; Clagett, G.P. Steal syndrome complicating hemodialysis access. Cardiovasc. Surg. 1997, 5, 648-653. [CrossRef]

53. Gkotsis, G.; Jennings, W.C.; Malik, J.; Mallios, A.; Taubman, K. Treatment of High Flow Arteriovenous Fistulas after Successful Renal Transplant Using a Simple Precision Banding Technique. Ann. Vasc. Surg. 2016, 31, 85-90. [CrossRef] [PubMed]

54. Schneider, C.G.; Gawad, K.A.; Strate, T.; Pfalzer, B.; Izbicki, J.R. T-banding: A technique for flow reduction of a hyperfunctioning arteriovenous fistula. J. Vasc. Surg. 2006, 43, 402-405. [CrossRef] [PubMed]

55. De Palma, J.R.; Vannix, R.; Bahuth, J.; Abukurah, A. "Steal" syndrome, ischemia, congestive failure and periperhal neuropathy. Proc. Clin. Dial. Transplant Forum 1973, 3, 9-11.

56. Anderson, C.B.; Groce, M.A. Banding of arteriovenous dialysis fistulas to correct high-output cardiac failure. Surgery 1975, 78 , 552-554.

57. Van Hoek, F.; Scheltinga, M.; Luirink, M.; Pasmans, H.; Beerenhout, C. Banding of hemodialysis access to treat hand ischemia or cardiac overload. Semin. Dial. 2009, 22, 204-208. [CrossRef]

58. Odland, M.D.; Kelly, P.H.; Ney, A.L.; Andersen, R.C.; Bubrick, M.P. Management of dialysis-associated steal syndrome complicating upper extremity arteriovenous fistulas: Use of intraoperative digital photoplethysmography. Surgery 1991, 110, 664-670.

59. Bourquelot, P.; Gaudric, J.; Turmel-Rodrigues, L.; Franco, G.; Van Laere, O.; Raynaud, A. Proximal radial artery ligation (PRAL) for reduction of flow in autogenous radial cephalic accesses for haemodialysis. Eur. J. Vasc. Endovasc. Surg. 2010, 40, 94-99. [CrossRef]

60. Chemla, E.S.; Morsy, M.; Anderson, L.; Whitemore, A. Inflow reduction by distalization of anastomosis treats efficiently high-inflow high-cardiac output vascular access for hemodialysis. Semin. Dial. 2007, 20, 68-72. [CrossRef]

61. Loh, T.M.; Bennett, M.E.; Peden, E.K. Revision using distal inflow is a safe and effective treatment for ischemic steal syndrome and pathologic high flow after access creation. J. Vasc. Surg. 2016, 63, 441-444. [CrossRef]

62. Leake, A.E.; Winger, D.G.; Leers, S.A.; Gupta, N.; Dillavou, E.D. Management and outcomes of dialysis access-associated steal syndrome. J. Vasc. Surg. 2015, 61, 754-760. [CrossRef] [PubMed]

63. Goel, N.; Miller, G.A.; Jotwani, M.C.; Licht, J.; Schur, I.; Arnold, W.P. Minimally Invasive Limited Ligation Endoluminal-assisted Revision (MILLER) for treatment of dialysis access-associated steal syndrome. Kidney Int. 2006, 70, 765-770. [CrossRef] [PubMed]

64. Patel, M.S.; Davies, M.G.; Nassar, G.M.; Naoum, J.J. Open Repair and Venous Inflow Plication of the Arteriovenous Fistula Is Effective in Treating Vascular Steal Syndrome. Ann. Vasc. Surg. 2015, 25, 927-933. [CrossRef] [PubMed]

65. Miller, G.A.; Goel, N.; Friedman, A.; Khariton, A.; Jotwani, M.C.; Savransky, Y.; Khariton, K.; Arnold, W.P.; Preddie, D.C. The MILLER banding procedure is an effective method for treating dialysis-associated steal syndrome. Kidney Int. 2010, 77, 359-366. [CrossRef]

66. Sheaffer, W.W.; Hangge, P.T.; Chau, A.H.; Alzubaidi, S.J.; Knuttinen, M.-G.; Naidu, S.G.; Ganguli, S.; Oklu, R.; Davila, V.J. Minimally Invasive Limited Ligation Endoluminal-Assisted Revision (MILLER): A Review of the Available Literature and Brief Overview of Alternate Therapies in Dialysis Associated Steal Syndrome. J. Clin. Med. 2018, 7, 128-137. [CrossRef]

67. Shintaku, S.; Kawanishi, H.; Moriishi, M.; Banshodani, M.; Ago, R.; Tsuchiya, S. Modified MILLER banding procedure for managing high-flow access and dialysis-associated steal syndrome. J. Vasc. Access 2015, 16, 227-232. [CrossRef]

68. Yaghoubian, A.; de Virgilio, C. Plication as primary treatment of steal syndrome in arteriovenous fistulas. Ann. Vasc. Surg. 2009, 23, 103-107. [CrossRef]

69. Murray, B.M.; Rajczak, S.; Herman, A.; Leary, D. Effect of surgical banding of a high-flow fistula on access flow and cardiac output: Intraoperative and long-term measurements. Am. J. Kidney Dis. Off. J. Natl. Kidney Found. 2004, 44, 1090-1096. [CrossRef]

70. Hashimoto, T.; Akagi, D.; Yamamoto, S.; Suhara, M.; Deguchi, J.-O.; Sato, O. Short Interposition with a Small-Diameter Prosthetic Graft for Flow Reduction of a High-Flow Arteriovenous Fistula. J. Vasc. Surg. 2021, 73, 285-290. [CrossRef] 